\title{
Evaluation of absorption efficiency of Zeolite ZSM-5 in the removal of styrene vapors
}

\author{
Yazdani Aval M, $\mathrm{MSc}^{1}$, Mortazavi SB, $\mathrm{PhD}^{2 *}$, Asilian Mahabadi $\mathrm{H}, \mathrm{PhD}^{2}$ \\ 1- MSc in Occupational Health Engineering, Dept. of Occupational Engineering, Faculty of Medical Sciences, Tarbiat \\ Modares University, Tehran, Iran. 2- Assistant Prof., Dept. of Occupational Engineering, Faculty of Medical Sciences, \\ Tarbiat Modares University, Tehran, Iran.
}

\begin{abstract}
Received: April 2016, Accepted: October 2016

Background: Volatile organic compounds (VOCs) are one of the most important and prevalent air pollutants. The vapor produced as a result of the vaporization of these compounds, even at very low concentrations, is harmful to the environment and human health. Thus, the aim of this study was to evaluate the removal of styrene vapor from the air flow using Zeolite (ZSM-5) in a continuous flow reactor.
\end{abstract}

Materials and Methods: This cross-sectional study was conducted at a laboratory scale. Styrene concentrations of 200 and $300 \mathrm{ppm}$ were selected for this study and steam saturation method was used to obtain the desired dynamic concentration. The desired concentration of dynamic styrene vapor was prepared in a fireproof cubic continuous flow reactor (canopy). ZSM-5 was synthesized and ground in a flat steel plate with standard mesh number of 20-40 and was used to remove the styrene vapors. In order to evaluate the removal efficiency, two variables of time and initial concentration of pollutant were investigated. In addition, scanning electron microscopy (SEM), X-ray powder diffraction (XRD), the Brunauer-Emmett-Teller (BET) technique, and energy-dispersive X-ray spectroscopy (EDX) were used to investigate the surface and quality of the obtained adsorbent.

Results: The results of SEM and XRD indicated the uniform surface and high purity of the synthesized zeolite. Adsorption breakthrough and saturation for $200 \mathrm{ppm}$ of styrene concentration occurred in the first 35 and 510 minutes of the experiment, and for $300 \mathrm{ppm}$ of styrene concentration, occurred 23 and 385 minutes after the beginning of the test, respectively,.

Conclusions: ZSM-5 showed a high level of efficiency in the removal of styrene vapors from polluted air; thus, it can be used to remove this pollutant from large industrial environments.

Keywords: Styrene, Zeolites, Indoor Air, Absorption, Efficiency, Volatile Organic Compounds, Adsorption.

\section{Introduction}

Industrial development, in addition to human welfare, has resulted in numerous problems such as environmental pollution especially air pollution which has gradually become one of the major concerns of human communities (1). Volatile organic compounds (VOCs) are one of the most important and prevalent air pollutants. VOCs are carbon compounds which participate in photochemical reactions in the atmosphere (2). The vapor produced as a result of the vaporization of these compounds, even at very low concentrations, are harmful to the environment and human health (3); thus, the controlling of VOCs emissions is one of the most important prerequisites to observing the environmental protection rules in industrial settings. Styrene monomer $(\mathrm{C} 6 \mathrm{H} 5 \mathrm{CH}=\mathrm{CH} 2)$ is a VOC which is largely used in different industries. This substance is an oily VOC (4) which is usually produced as a result of the catalytic reaction of dehydrogenation and hydroperoxidation of ethylbenzene $(5,6)$. Styrene monomer is primarily used for the production of polystyrene (7). It is also used in

\footnotetext{
Corresponding author: Seyyed Bagher Mortazavi, Dept. of Occupational Engineering, Faculty of Medical Sciences, Tarbiat Modares University, Tehran, Iran. E-mail: mortazav@modares.ac.ir
} 
different industries for the production of color, plastics, plastic coatings, artificial rubber, synthetic rubber, coatings, pipes, fittings, tanks, lighting tools, and corrosion-resistant products (6). This material may be absorbed by the body through inhalation, ingestion, and contact with the eyes and skin, leading to complications in the body. Among the complications and side effects caused by styrene we may note negative effects on the central nervous system, loss of concentration, fatigue, nausea, irritant contact dermatitis, and negative effects on the reproductive system (8). Results of a study by Vodicka et al. showed that exposure to styrene at concentrations of $10 \mathrm{ppm}$ to $100 \mathrm{ppm}$ and higher could cause irritation in the eyes, throat, and respiratory system (9). In addition, they reported that at a concentration of $376 \mathrm{ppm}$, it could increase nasal mucus secretion (9). In another study, Cherry and Gautrin reported that $23 \%$ and $71 \%$ of those, respectively, exposed to concentrations of less than $50 \mathrm{ppm}$ and higher than $100 \mathrm{ppm}$ had decreased level of central and peripheral nervous system activity (10). Based on the classification of the International Agency for Research on Cancer (IARC), styrene is classified in the possibly carcinogenic to humans group (11).

Previous studies have shown that many methods have been used to remove styrene from air in different workplaces $(11,12)$. However, most presented removal methods have some disadvantages that limit their use (13). Surface absorption method is one of the most commonly used processes for the removal of VOCs (14). In several studies, the efficiency of adsorbents in the removal of VOCs, such as styrene, has been proven (1518). Among these adsorbents, active carbon and zeolite have been studied more. Although the specific surface area of active carbon is higher, zeolites have more arranged crystalline structures, compared to other adsorbents like active carbon and silica gel, so all the pore diameters in zeolites are similar and uniform. On the other hand, in recent years, zeolite has received more attention due to its unique properties such as crystallization, high surface area, acidity, and ion exchange capacity (19).

Zeolite (ZSM-5) is a type of zeolite which has high thermal resistance, high surface area, and low porosity; as a result, it is largely used for reduction and photo catalytic oxidation of organic compounds (20). To the best of our knowledge, no study has been performed on the use of this adsorbent for the removal of styrene from air stream. Therefore, the aim of this study was to investigate the removal of styrene from polluted air by ZSM-5 in a dynamic system.

\section{Materials and Methods}

This cross-sectional study was conducted at a laboratory scale. The desired concentration of dynamic styrene vapor was prepared using steam saturation method in a fireproof cubic continuous flow reactor (canopy).

Preparation of Zeolite ZSM-5: The synthetic compounds with a composition ratio of 2O:60SiO2:0.5 Al2O3:936H2O TPA (12-Otetradecanoylphorbol-13-acetate) was prepared by adding aluminum sulfate and silica to ammonium hydroxide solution $20 \% \mathrm{w} / \mathrm{w}$ in boiling water. After 10 minutes of stirring under reflux condition, a clear homogeneous solution was obtained. Then, the solution temperature was lowered to $25{ }^{\circ} \mathrm{C}$. This transparent solution was poured into flasks that were placed in an oil bath containing reflux. Crystallization occurred at ambient pressure and at a temperature of $80^{\circ} \mathrm{C}$ for 72 hours. The obtained zeolite nanoparticles were separated from the solution via centrifugation at 5000 rpm. They were poured into distilled water and separated again using ultrasonic bath in order to obtain the concentrated colloidal suspension. To classify the sizes of ZSM-5 standard sieves with a mesh of 20 and 40 (ASTM, PA, USA) were, respectively, used to separate particle sizes of 0.85 and $0.425 \mathrm{~mm}$. ZSM-5 with 20-40 mesh included particles that passed through the 20-mesh sieve, but remain on the 40-mesh sieve. Scanning electron microscopy (SEM), X-ray powder 
diffraction (XRD), Brunauer-Emmett-Teller (BET) technique, and energy-dispersive X-ray spectroscopy (EDX) were used to assess the surface and quality of the obtained adsorbent.

Reactor Design: The reactor system was a cube-shaped chamber with a length of $26 \mathrm{~cm}$, a width of $10 \mathrm{~cm}$, and a height of $15 \mathrm{~cm}$ (height of the reactor: $6 \mathrm{~cm}$ ) and its base was like a canopy. Polluted air entered the cubeshaped chamber from the top and exited from the bottom (the canopy part). At a height of 5 $\mathrm{cm}$ from the chamber's floor there was a stainless steel plate (standard mesh number of 40), on which 38.6 grams of heated ZSM-5 with a uniform distribution and a thickness of $2 \mathrm{~mm}$ was placed. Figure 1 shows a threedimensional image of the reactor.

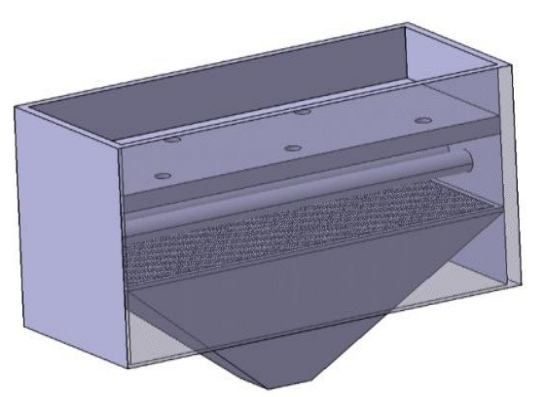

Figure 1: The three-dimensional image of the designed reactor

Concentration system: In order to supply the entrance air a $51 \mathrm{w}$ pump with $147.11 \mathrm{mmHg}$ pressure (Hitachi Ltd., Tokyo, Japan,) was used. For the removal of probable pollutants and controlling of humidity, the entrance air was passed through a vessel containing an activated charcoal bed and silica gel, and then, was entered into the concentration system.

Due to the likelihood of increasing of pump temperature during the experiment and the subsequent warming of the outlet air, the exhaust air tubes of the pump were placed into a plastic container filled with water so that it would reach the laboratory ambient temperature. The exhaust tube (which was placed inside the plastic container filled with water) was made of aluminum so that the air passing the tube could easily transfer its heat to the surrounding environment. The high heat capacity of water and high surface area of the plastic graduated cylinder helped to prevent significant change in the temperature of the glass thermometer placed in the water during the experiment. In addition, the high length (2 m) of the pump's exhaust tube helped the air reach the laboratory ambient temperature. In this study, different concentration systems were evaluated, and ultimately, the steam saturation concentration system was used. For this purpose, a $500 \mathrm{ml}$ gas washer bottle (Shot Co., Germany) was used. In order to ensure the accuracy of the operation, 3 alcohol thermometers were used; one was attached to the outer wall of the liquid container exactly next to a thermocouple sensor, another was placed in the chamber, and the third one was placed outside the isothermal box. Accordingly, the temperature outside the chamber and the accuracy of the displayed numbers were continuously monitored using a digital thermocouple.

Method of analysis: To evaluate the performance of the adsorbent, styrene, at the two concentrations of 200 and 300 PPM, was injected into the designed reactor. Using an automatic meter reading device (Model 5000, PhoCheck, UK) that works via Photo Ionization Detection (PID) method, the concentration of styrene in the air exiting the chamber was measured at intervals of 10 minutes. In order to ensure the accuracy of the collected data, each of the measurements was repeated at least 3 times. In order to ensure the accuracy of the measured data, the concentration of some random samples were also measured using gas chromatography (GC) (Model PU 4410, Philips, Amsterdam, Netherlands) which was equipped with a flame ionization detector (FID). Using a $5 \mathrm{ml}$ gas syringe, $3 \mathrm{ml}$ of the pollutant was quickly injected through the injector each time. Columns were used in the devices of the type Pack (length of $1.5 \mathrm{~m}$ and diameter of $4 \mathrm{~mm}$ ). In order to conduct the decomposition, the standard 89 proposed by the Occupational Safety and Health Administration (OSHA) 
was followed which suggested a thermal plan of $200{ }^{\circ} \mathrm{C}$ for the injector, $250{ }^{\circ} \mathrm{C}$ for the detector, and $100{ }^{\circ} \mathrm{C}$ for the column. Nitrogen (33 $\mathrm{ml} /$ minute) was used as the carrier gas. It was found that the PhoCheck and GC results were very close to each other and had a correlation $\left(\mathrm{R}^{2}=0.977\right)$. Finally, in order to ensure the repeatability of the results, each experiment was repeated at least 3 times. Excel software (version 2013, Microsoft, Redmond, WA, USA) was used to draw the charts.

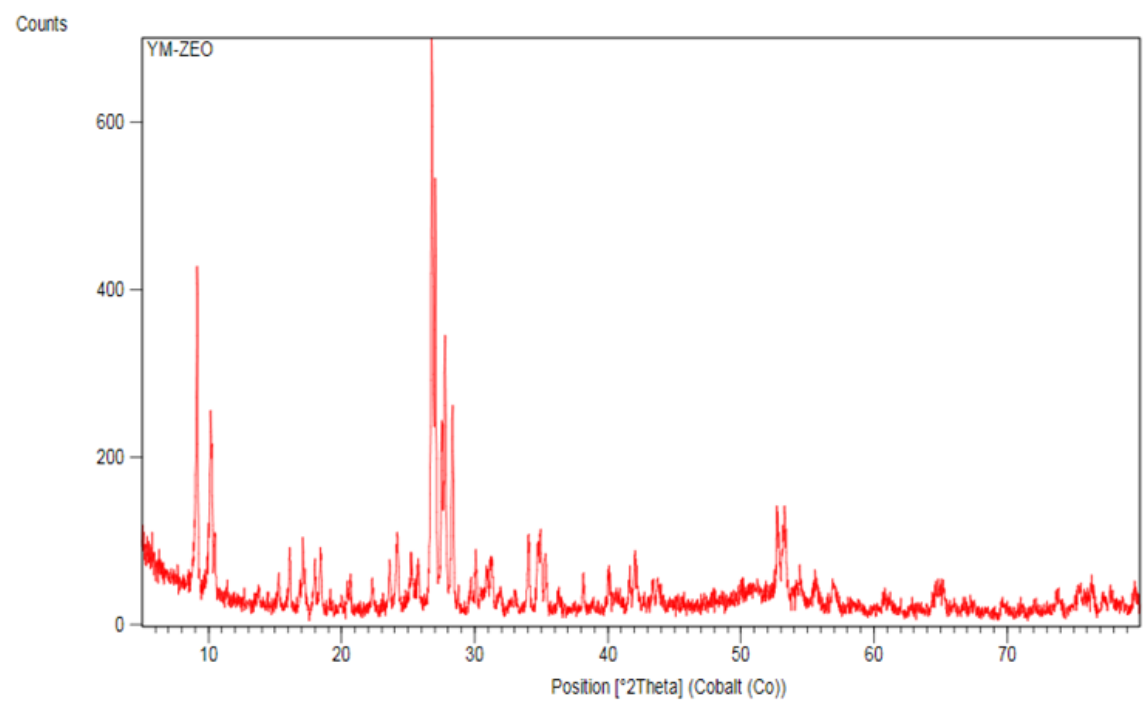

Figure 2: XRD pattern of synthesized Zeolite Socony Mobil-5

\section{Results}

Structural properties of Zeolite ZSM-5: Figure 2 shows the XRD patterns. The results showed a very good relationship between the crystal structure of the synthetized samples and the crystal structure of ZSM-5 catalyst described in the references. According to figure 2, the main peak of ZSM-5 crystal is $2 \theta$ $=28^{\circ}$, with an intensity of about 700 counts. This shows that calcination temperature can be increased, but, because of surface area, this temperature is at its optimum.

Table 1: The results of the Scherrer equation

\begin{tabular}{cccc}
\hline $\boldsymbol{\Lambda}(\boldsymbol{\AA})$ & $\boldsymbol{\theta}$ (radians) & FWHM $^{*}($ radians) & Crystal size (nm) \\
\hline 1.78901 & 0.4682 & $6.87 \times 10^{-3}$ & 23.37 \\
\hline
\end{tabular}

* Peak Width-Full Width at Half Maximum

The Scherrer equation was used to calculate the ZSM-5 particle size. The results obtained from the mentioned equation are presented in table 1 .
The specific surface area, total pore volume, and mean pore diameter of ZSM-5 was measured using the BET technique. Table 2 shows the results of the BET method.

Table 2: Results of the Brunauer-Emmett-Teller analysis

\begin{tabular}{cccc}
\hline Sample & $\begin{array}{c}\text { Specific surface area } \\
\left(\mathbf{m}^{2} / \mathbf{g}\right)\end{array}$ & $\begin{array}{c}\text { Mean pore diameter } \\
(\mathbf{n m})\end{array}$ & $\begin{array}{c}\text { Total pore volume } \\
\left(\mathbf{c m}^{3} / \mathbf{g}\right)\end{array}$ \\
\hline ZSM5 & 529.24 & 2.3026 & 0.3047 \\
\hline
\end{tabular}

ZSM-5: Zeolite Socony Mobil-5 


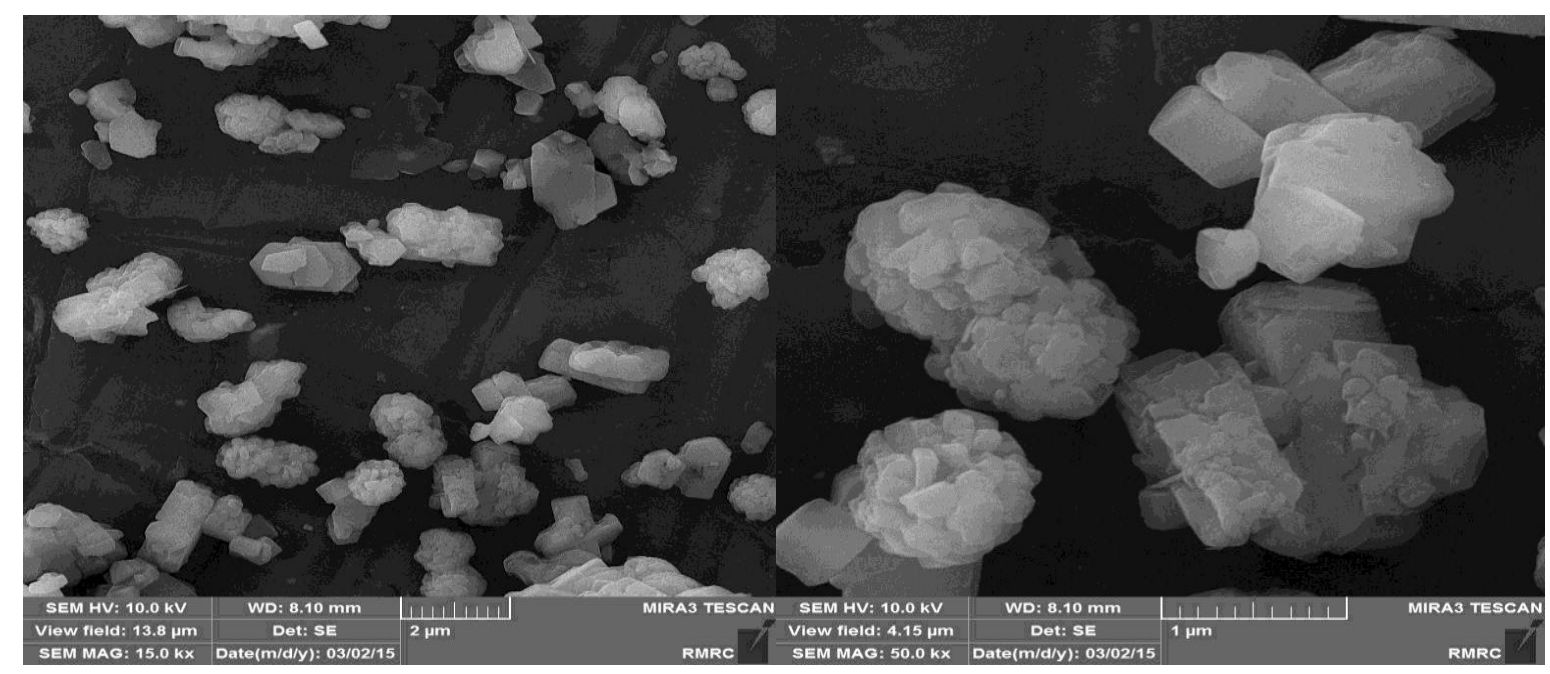

Figure 3: Scanning Electron Microscopy images of Zeolite ZSM-5 at different magnifications

Based on the results of BET analysis, the surface area of ZSM-5 was $529.24 \mathrm{~m}^{2} / \mathrm{g}$ which suggested a significant increase in specific surface area of ZSM-5 as compared with the industrial samples (21).

The morphology of the samples was evaluated using SEM at a high magnification. The images obtained from SEM analysis are shown in figure 3. As shown in figure 3, ZSM-5 particles have a uniform size distribution and specific geometric shape close to a cube or rectangular cube.

The results of EDX analysis of synthesized ZSM-5 are shown in figure 4 . The presence of $\mathrm{O}, \mathrm{Si}$, and $\mathrm{Al}$ in EDX elemental analysis can be observed which is indicative of the composition of the zeolite (zeolite is a type of aluminum silicate).

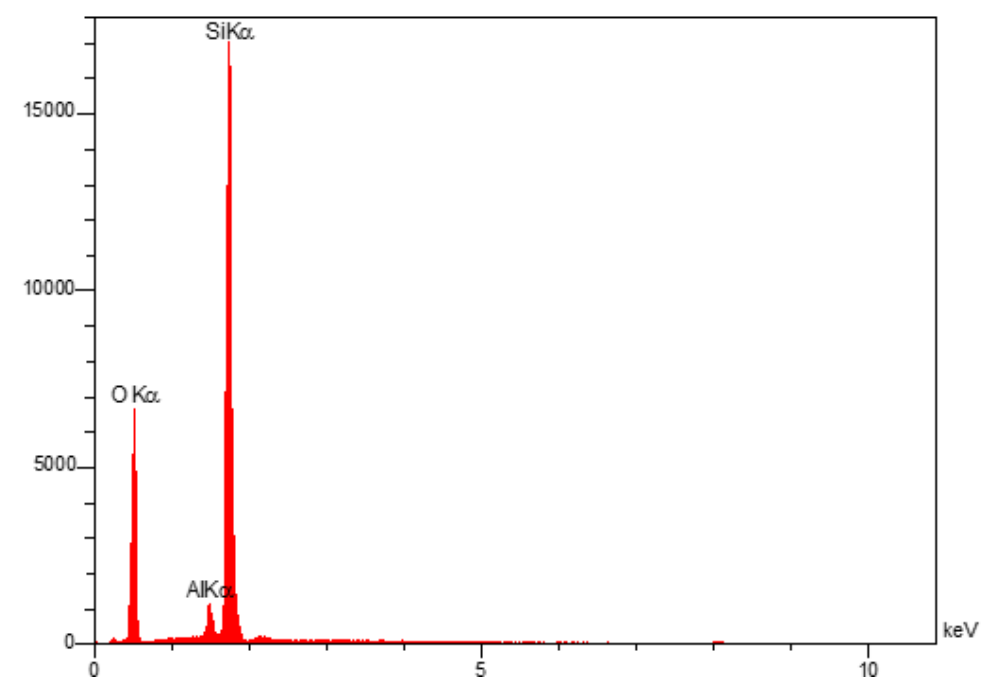

Figure 4: Structure of the synthesized Zeolite ZSM-5 analyzed via energy-dispersive X-ray spectroscopy

Regarding the peak obtained by the device, it should be mentioned that this method usually determines components heavier than the carbon which exists in the surface layer of the adsorbents. In this method, the device calculates the amount of each element at every desired sample surface through the integration of the graph surface of each element. The graph shows that silica and aluminum are among the important elements which exist in the structure of the studied zeolite. The results of this analysis showed that the ZSM-5 used in this study contained silica $(27.91 \%)$ and aluminum $(1.56 \%)$. The presence of 
$\mathrm{SiO}_{2} / \mathrm{Al}_{2} \mathrm{O}_{3}$ is one of the factors affecting the zeolite absorption rate. The proportion of $\mathrm{SiO}_{2} / \mathrm{Al}_{2} \mathrm{O}_{3}$ in the studied ZSM-5 was calculated as 19.88. This is compared with other commercial samples of ZSM-5 with different $\mathrm{SiO}_{2} / \mathrm{Al}_{2} \mathrm{O}_{3}$ ratios in table 3. As can be seen in table 3 , with the decreasing of $\mathrm{SiO}_{2} / \mathrm{Al}_{2} \mathrm{O}_{3}$ ratio, the specific area of zeolite was increased.

Table 3: Comparison of the Zeolite ZSM-5 synthesis used in the present study and other commercial samples of Zeolite ZSM-5

\begin{tabular}{cccc}
\hline Zeolite type & Company & $\mathbf{S i O}_{\mathbf{2}} / \mathbf{A l}_{\mathbf{2}} \mathbf{O}_{\mathbf{3}}$ & Surface $\mathbf{a r e a}\left(\mathbf{m}^{\mathbf{2}} / \mathbf{g}\right)$ \\
\hline ZSM-5 & Zeolyst(CBV 2314) & 23 & 425 \\
ZSM-5 & Zeolyst(CBV 28014) & 28 & 400 \\
ZSM-5 & Present study & $19 / 88$ & $529 / 24$ \\
\hline
\end{tabular}

ZSM-5: Zeolite ZSM-5

The effect of time on the adsorption rate: Figure 5 shows the rate of styrene vapor absorption in an inlet concentration of 300 ppm by the ZSM-5 particles with 20-40 mesh at different times. In this experiment, after placing the ZSM-5 inside the reactor, the inlet air flow with a constant concentration was passed over the zeolite and the rate of vapor absorption over time was evaluated for all the samples. As shown in figure 5, at the beginning of the experiment, the absorption rate was about $100 \%$, and after a period of 23 minutes, it reached the break point $(5 \%$ of the inlet volume). Subsequently, the adsorption rate sharply reduced to the extent that, 395 minutes after the start of the experiment, the adsorbent was saturated; thus, the concentration of the input and output gases became the same and the absorption rate was reduced to 0 .

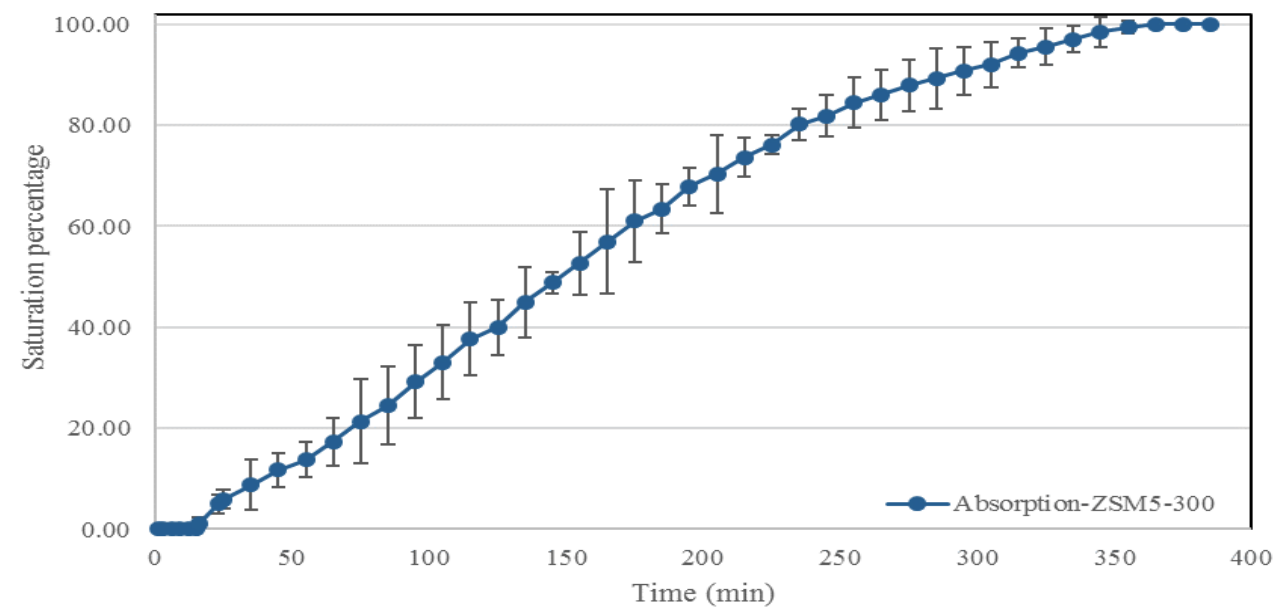

Figure 5: Changes in styrene vapor absorption by Zeolite ZSM-5 particles with 20-40 mesh at a concentration of $300 \mathrm{ppm}$ in a flow of $11 /$ minute

Effects of initial concentration on the absorption: In this study, the factors affecting the absorption rate (humidity and temperature) were kept constant, and the two concentrations of 200 and $300 \mathrm{ppm}$ were used to evaluate the effects of initial concentration on the absorption rate. Figure 6 presents the results of the analysis of the effects of initial concentration on the rate of absorption of the ZSM-5 particles with 20-40 mesh in a flow of $11 /$ minute at the two concentrations of 200 and $300 \mathrm{ppm}$. 


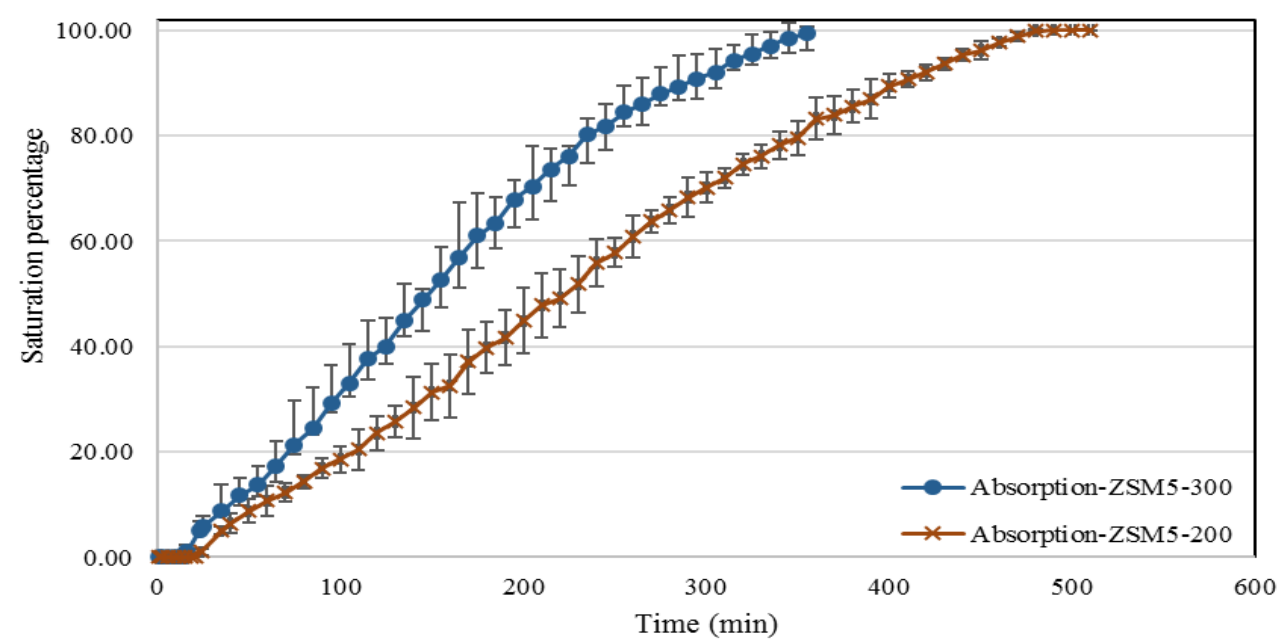

Figure 6: Effect of concentration on the time of absorption of Zeolite ZSM-5 particles with 20-40 mesh in a flow of $11 /$ minute

As shown in figure 6, using ZSM-5 particles with 20-40 mesh at a concentration of 300 ppm in a flow of 1 1/minute, styrene adsorption break point through and saturation for 200 ppm of styrene concentration occurred, respectively, in the first 35 and 510 minutes of experiment time. Moreover, for $300 \mathrm{ppm}$ concentration of styrene, this occurred 23 and 385 minutes after the beginning of the test, respectively.

The effect of concentration on the absorption area: The effect of inlet concentration on the absorption area was assessed by calculating the areas under the curve. The area under the curve was calculated using equation 1 , and the results are shown in figure 7 .

$$
A=\frac{(y 1+y 2) *(x 2-x 1)}{2} \quad \text { Equation (1) }
$$

In this equation, $\mathrm{x}$ is time (horizontal axis) and $\mathrm{y}$ is the output concentration (vertical axis).

As shown, for ZSM-5 particles with 20-40 mesh, the absorption area was $59607.42 \mathrm{~m}^{2}$ at a concentration of $300 \mathrm{ppm}$ and $50607.97 \mathrm{~m}^{2}$ at a concentration of $200 \mathrm{ppm}$.

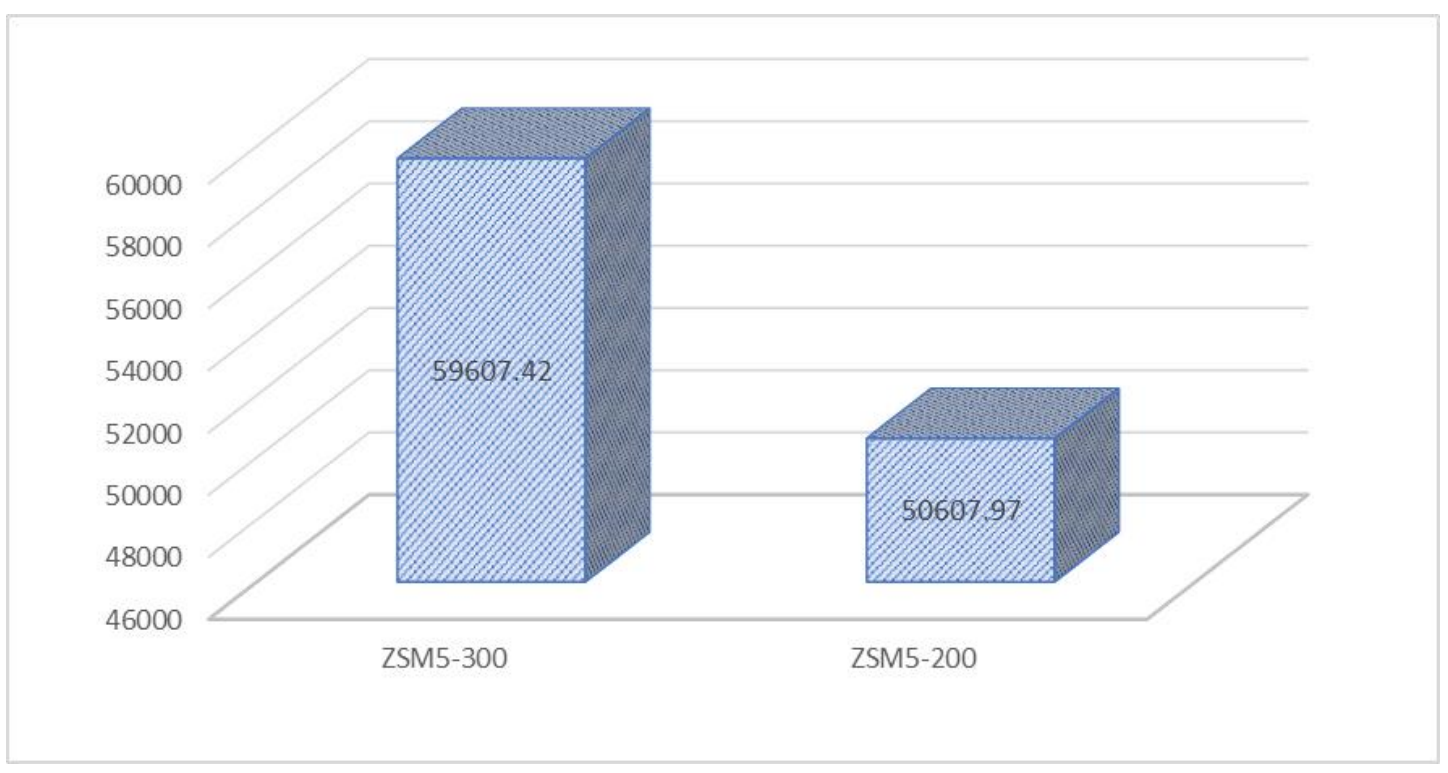

Figure 7: Area under the curve calculated for the initial inlet concentrations of 200 and $300 \mathrm{ppm}$ 


\section{Discussion}

In this study, ZSM-5 was used to absorb styrene vapors from the air using a continuous flow reactor. The variables of time and initial concentrations of pollutants were measured to evaluate the performance of this adsorbent. XRD pattern was used to assess the particle size and structural properties of ZSM-5. The lack of any additional peak in the XRD pattern of synthetic ZSM-5 was indicative of its purity which could increase the efficiency of the removal process. Moreover, the results of SEM showed that synthesized zeolite particles had an equal size which can increase the efficiency of zeolite in the styrene removal process. Wen Liang et al. used XRD to characterize nanoparticles (23). Taking into consideration the peaks in XRD curve, they determined the purity of titanium dioxide nanoparticles used in their study. They concluded that the purity of the prepared adsorbent could increase the efficiency of the adsorbent (22).

In this study, the effects of the two initial concentrations of 200 and 300 ppm were investigated. The results showed that with increasing the initial concentration, the efficiency of ZSM-5 in the absorption of styrene decreased. When the initial concentration of styrene increases, the absorption efficiency decreases which is due to the reduction in the number of pores on the surface of ZSM-5. The analysis also showed that an increase in the concentration of styrene gas flow reduced the time of reaching saturation and the cutoff point. With increasing the concentration of the absorbing element, the speed of the absorption process increases which is due to the presence of a large number of gas molecules of the absorbing element that increases their transfer and contact with the adsorbent surface (23, 24).

As a result, by increasing the concentration of styrene gas at a constant flow rate, zeolite could reach the cutoff point earlier. The results of this study are in line with that of Golbabaei et al. (25). In this study, with increase in the absorption bed depth, the absorption capacity of zeolite increased; however, with increase in air flow rate and inlet concentration, the absorption capacity decreased. In another study, the researchers investigated benzene absorption on two types of activated carbon; the first type was prepared from the wood composites cutting dust and the second type was a commercially supplied activated carbon prepared from coconut shell(26). Asilian et al. reported that in the sampling of benzene as a VOC in ambient air by clinoptilolite zeolite, the mesh number of $80 / 60$ compared to the mesh number of $60 / 40$ has longer breakthrough time (27). Therefore, the mesh number of $80 / 60$ was determined as the optimum mesh for sampling of benzene in air. Moreover, a study was conducted on toluene (28). Similar to the study by Asilian et al., the results of the study on toluene showed that with increasing the concentration of styrene, the absorption capacity decreased. Furthermore, the absorption capacity of toluene on both types of activated carbon and in all the tested conditions was higher than the absorption capacity of benzene (27). LiloRoudnas et al. conducted a study to investigate the effects of competitive adsorption of benzene-toluene composition with a concentration of $200 \mathrm{ppm}$ on 8 different samples of activated carbon (26). They reached similar results. The cutoff points of the mentioned studies show that with increasing of the concentration of inlet gas, the saturation time and the absorption efficiency decreased (25).

Surface area was the other important factor which was examined in the tests. The results of the current study suggested that with increasing the concentration of styrene, the number of molecules at the surface and adsorbent mass increased which in turn increased the surface area and styrene absorption capacity. The increase in absorption capacity might be attributed to the fact that with the increase in adsorbent mass, the number of active sites on the adsorbent also 
increases. As a result, there will be an increase in contact area between the adsorbent and pollutants; this enhances the efficiency of styrene removal. According to the study by Afzali et al., the increase in gas concentration reduced the cutoff point and saturation in $77.8 \%$ and $55.6 \%$ of experiments, respectively. In another study, with increase in the concentration of the pollutant, the probability distribution of pollutants in the pores of the adsorbent, and thus, the absorption rate also increased. The results of the present study are consistent with the results of the mentioned studies $(3,28)$.

A limitation of this study was that some effective parameters such as humidity, adsorbent particle size, and higher concentrations of styrene were not controlled.

\section{Conclusion}

ZSM-5 synthesized in the laboratory had high efficiency in the removal of styrene from polluted air; in the first 20 minutes of the experiment, the removal rate was about $100 \%$. Its morphological features, uniformity, and high purity had a significant impact on its absorption efficiency. This adsorbent can be used in larger scales to remove styrene. Given the high efficiency of this adsorbent, further studies on the removal of other organic pollutants from the air flow in indoor and closed environments by this adsorbent are suggested. It is also suggested that future studies investigate other parameters affecting the removal efficiency.

\section{Acknowledgment}

The authors of this paper would like to express their thanks and appreciation to the Research Deputy of Tarbiat Modares University who supported the researchers in conducting this study.

Conflict of interest: None declared

\section{Reference}

1. Cooper CD, Alley FC. Air pollution control: A design approach. $4^{\text {th }}$ ed. Florida, United States: Waveland Pr Inc; 2010.

2. Thitakamol B, Veawab A, Aroonwilas A. Environmental impacts of absorption-based CO 2 capture unit for post-combustion treatment of flue gas from coal-fired power plant. International Journal of Greenhouse Gas Control 2007; 1(3):318-42.

3. Lillo-Ródenas MA, Cazorla-Amorós D, Linares-Solano A. Behaviour of activated carbons with different pore size distributions and surface oxygen groups for benzene and toluene adsorption at low concentrations. Carbon N Y 2005; 43(8):1758-67.

4. Lim M, Rudolph V, Anpo M, Lu GQM. Fluidized-bed photocatalytic degradation of airborne styrene. Catal Today 2008; 131(14):548-52.

5. Maciá-Agulló JA, Cazorla-Amorós D, LinaresSolano A, Wild U, Su D, Schlögl R. Oxygen functional groups involved in the styrene production reaction detected by quasi in situ XPS. Catal Today 2005; 102:248-53.

6. Cavani F, Teles JH. Sustainability in catalytic oxidation: an alternative approach or a structural evolution? ChemSusChem 2009; 2(6):508-34.

7. Greenberg MI. Occupational, industrial, and environmental toxicology. $1^{\text {st }}$ ed. Amsterdam, Netherlands: Elsevier Health Sciences; 2003.

8. Winder Ch, Stacey NH. Occupational toxicology. $2^{\text {nd }}$ ed. Boca Raton, Florida, United States: CRC Press; 2004.

9. Vodicka P, Koskinen M, Arand M, Oesch F, Hemminki K. Spectrum of styrene-induced DNA adducts: the relationship to other biomarkers and prospects in human biomonitoring. Mutat Res Rev Mutat Res 2002; 511(3):239-54.

10. Cherry N, Gautrin D. Neurotoxic effects of styrene: further evidence. Br J Ind Med 1990; 47(1):29-37.

11. Djeribi R, Dezenclos T, Pauss A, Lebeault JM. Removal of styrene from waste gas using a biological trickling filter. Eng Life Sci 2005; 5(5):450-7.

12. Khan FI, Ghoshal AK. Removal of volatile organic compounds from polluted air. J Loss Prev Process Ind 2000; 13(6):527-45.

13. Yin $\mathrm{J}, \mathrm{Wu} \mathrm{H}$, Thiyagarajan $\mathrm{M}$, Hong $\mathrm{SE}$, Neisser M, Cao Y. Methods and materials for removing metals in block copolymers. Az Electronic Materials (Luxembourg) S.A.R.L.; 2015 May; No.: US9040659 B2

14. Ikhlaq A, Brown DR, Kasprzyk-Hordern B. Catalytic ozonation for the removal of organic 
contaminants in water on ZSM-5 zeolites. Appl Catal B 2014; 154-155:110-22.

15. Abumaizar RJ, Kocher W, Smith EH. Biofiltration of BTEX contaminated air streams using compost-activated carbon filter media. J Hazard Mater 1998; 60(2):111-26.

16. Mathur AK, Majumder CB, Chatterjee S. Combined removal of BTEX in air stream by using mixture of sugar cane bagasse, compost and GAC as biofilter media. J Hazard Mater 2007; 148(1-2):64-74.

17. Aizpuru A, Malhautier L, Roux JC, Fanlo JL. Biofiltration of a mixture of volatile organic compounds on granular activated carbon. Biotechnol Bioeng 2003; 83(4):479-88.

18. Dehghanzadeh R, Torkian A, Bina B, Poormoghaddas H, Kalantary A. Biodegradation of styrene laden waste gas stream using a compost-based biofilter. Chemosphere 2005; 60(3):434-9.

19. Pérez-Ramírez J, Christensen CH, Egeblad K, Christensen $\mathrm{ChH}$, Groen JC. Hierarchical zeolites: enhanced utilisation of microporous crystals in catalysis by advances in materials design. Chem Soc Rev 2008; 37(11):2530-42.

20. Song W, Justice RE, Jones CA, Grassian VH, Larsen SC. Synthesis, characterization, and adsorption properties of nanocrystalline ZSM5. Langmuir 2004; 20(19):8301-6.

21. Zhu H, Liu Z, Kong D, Wang Y, Yuan X, Xie Z. Synthesis of ZSM-5 with intracrystal or intercrystal mesopores by polyvinyl butyral templating method. J Colloid Interface Sci 2009; 331(2):432-8.
22. Gao W, Jin R, Chen J, Guan X, Zeng H, Zhang $\mathrm{F}$, et al. Titania-supported bimetallic catalysts for photocatalytic reduction of nitrate. Catal Today 2004; 90(3-4):331-6.

23. Curcio MS, Oliveira MP, Waldman WR, Sánchez B, Canela MC. TiO2 sol-gel for formaldehyde photodegradation using polymeric support: photocatalysis efficiency versus material stability. Environ Sci Pollut Res Int 2014; 22(2):800-9.

24. Golbabaei F, Rahmanzadeh E, Moussavi GR, Faghihi zarandi A, Baneshi MR. Fixed bed adsorption of hexavalent chromium onto natural zeolite from air stream. Journal of Health and Safety at Work 2014; 4(2):1-14.

25. Lillo-Ródenas MA, Fletcher AJ, Thomas KM, Cazorla-Amorós D, Linares-Solano A. Competitive adsorption of a benzene-toluene mixture on activated carbons at low concentration. Carbon N Y 2006; 44(8):145563.

26. Deng B, Kim ES. Co-adsorption of trichloroethylene and arsenate by ironimpregnated granular activated carbon. Water Environ Res 2016; 88(5):394-402.

27. Asilian H, Khavanin A, Afzali M, Dehestani S. Removal of styrene from air by natural and modified zeolite. Health Scope 2012; 1(1):711.

28. Davis WT, Air \& Waste Management Association. Air pollution engineering manual. $2^{\text {nd }}$ ed. New York, United States,: John Wiley \& Sons, Inc.; 2000. 